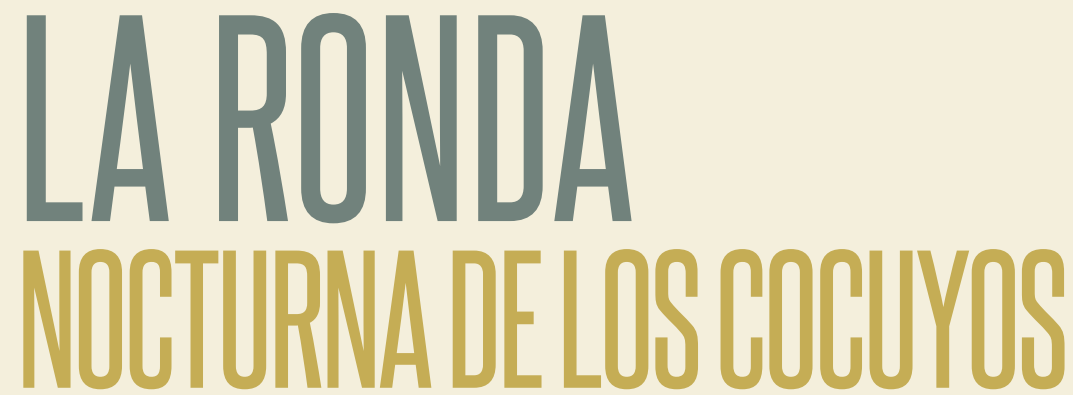

\title{
Lino Monanegii
}

Esta historia habla de una mascarada, de un baile secreto de medianoche, distinto y similar, quizá, al narrado por Arthur Schnitzler en Traumnovelle, pero situado lejos de las calles nevadas de la Viena invernal.

\author{
$\mathrm{L}[\mathrm{os}]$ muchach [os] pasaban \\ [como cocuyos \\ con un incendio de ámbar a la \\ [grupa, \\ y en nuestros rostros de ángeles \\ [ardían canciones y alcoholes \\ con una llama impúdica e impune.
}

Gilberto Owen,

"Discurso del paralítico"

\section{Advertencia al lector}

econozco mi afición por la impertinencia. Sé que no es una virtud sino un mal rasgo de mi personalidad. Confieso que me entrego con facilidad e incluso disfruto intervenir, inoportunamente, en medio de la comida, de la sobremesa y en la conversación de media tarde en el café, con alguna anécdota o historia tremendista, soez y, en algunos casos, ofensiva. Dada esta inclinación no me basto con expe- riencias propias, por lo que echo mano también de las ajenas; es decir, busco, memorizo y colecciono historias truculentas, tremebundas, cuanto más "escandalizantes", mejor. Gasto parte de mis energías en extraer este tipo de relatos a mis amigos y conocidos; los palpo hablando metafóricamente- para ver si por sobre la superficie de la conversación encuentro una veta por la que se asome -como un bichouna anécdota de tal tipo. Hallada alguna, la dejo madurar entre la conversación ocasional y un buen día, tarde o noche, sale sin más, desprevenida, lista para mis oídos; lista para prenderla de un ala apenas pretenda volar recelosa. Después de la captura, con la ayuda de delicadas pinzas, la deposito en la cámara húmeda de mi memoria, sostenida penosamente con un alfiler que la atraviese por en medio. Allí, la historia - el relato-dormita junto con otros que forman $\mathrm{mi}$ colección, cada uno dentro de su cajón, como si se tratase del más variopinto catálogo de coleópteros de un taxidermista experto, hasta que, llegado su momento, la historia sale de mi boca aderezada de nuevos colores, olores y texturas. Sus protagonistas ya no son los mismos, se trasmutan según el momento y la circunstancia.

No obstante, confieso que, de entre todas, una es mi predilecta: será por ese motivo que es la que más versiones tiene de sí misma. La historia, después de contarla - una vez tras otra-, se ha contaminado más y más de ficción; tan es así que lo real en ella se ha diluido por completo, transita -como afirma Enrique Vila-Matas- por ese territorio deliberadamente indefinido que siempre ha existido sobre [lo] que es real e imaginado.

El origen de esta anécdota es incierto y carece de importancia. Su veracidad es cuestionable, no así su originalidad. No hago mayores advertencias que estas. Acaso, antes de narrarla, cabría recordar que, como mencioné líneas arriba, esta versión no será la misma en una siguiente ocasión.

$$
* * *
$$

Esta historia habla de una mascarada, de un baile secreto de medianoche, distinto y similar, quizá, al narrado por Arthur Schnitzler en Traumnovelle, pero situado lejos de las calles nevadas de la Viena invernal. Por lo contrario, tiene lugar en un sitio menos septentrional, donde la nieve apenas se ve desde lejos sobre las crestas de las montañas que se alzan muy lejos de la costa, y el tiempo en el que sucedió es contingente. No me consta que haya ocurrido más de una vez, pero especulo al decir que así fue. De cuando en cuando ocurría, pues, un baile, uno como el que se celebró, muchísimos años atrás, en el noviembre porfirista de 1901 en la capital del país, en 
la calle De la Paz, hoy llamada Ezequiel Montes, de la colonia Tabacalera. Esta velada, sin embargo, no tenía como escenario las calles porfirianas de la Ciudad de México, y tampoco sucedió en un tiempo $\tan$ lejano. Pues bien, en este encuentro se reunían todos los invitados -varones en su conjuntoen el viejo casco de una hacienda, en un poblado no muy lejos de una provinciana capital, cerca de un lugar perdido cuyo topónimo está dedicado al gatuno ocelote, deidad prehispánica.

La construcción principal de la finca, lugar de esta reunión clandestina, era una casa encalada, que brillaba blanca durante el día sobre una moqueta grande de hierba añil que se extendía larga y sin pliegues hasta la linde del río, un río angosto y argénteo donde las mujeres hacían la colada temprano con esos morenos brazos [que] exprimen la neblina de ropa azul, tal como escribió Novo. Sus aguas las poblaban redondos cantos grises y pequeños guijarros que la corriente revolvía como gusarapas. A veces el torrente impulsaba uno fuera del cauce, y este, lejos del agua, se hundía en el barro formando así el pedregal de la orilla del río que daba nombre a la propiedad y en el que los muchachos y niños del cortijo nadaban los días de estío, como en las pinturas uranistas de Ludwig von Hofmann: desnudos y matinales, con el pecho liso al descubierto, frágil que hasta se figuraba de cristal, y con los genitales contraídos-colgandejos- que parecían bellotas adornadas con un corsage púbico de hojas y flores diminutas de lino.

A la fiesta, además de los invitados, asistían muchachitos del poblado que el anfitrión - un cuarentón venezolano que vestía de riguroso liquiliqui y andaba siempre sentado en una silla parecida a las mecedoras, sobre dos enormes ruedas de madera, como de cele-

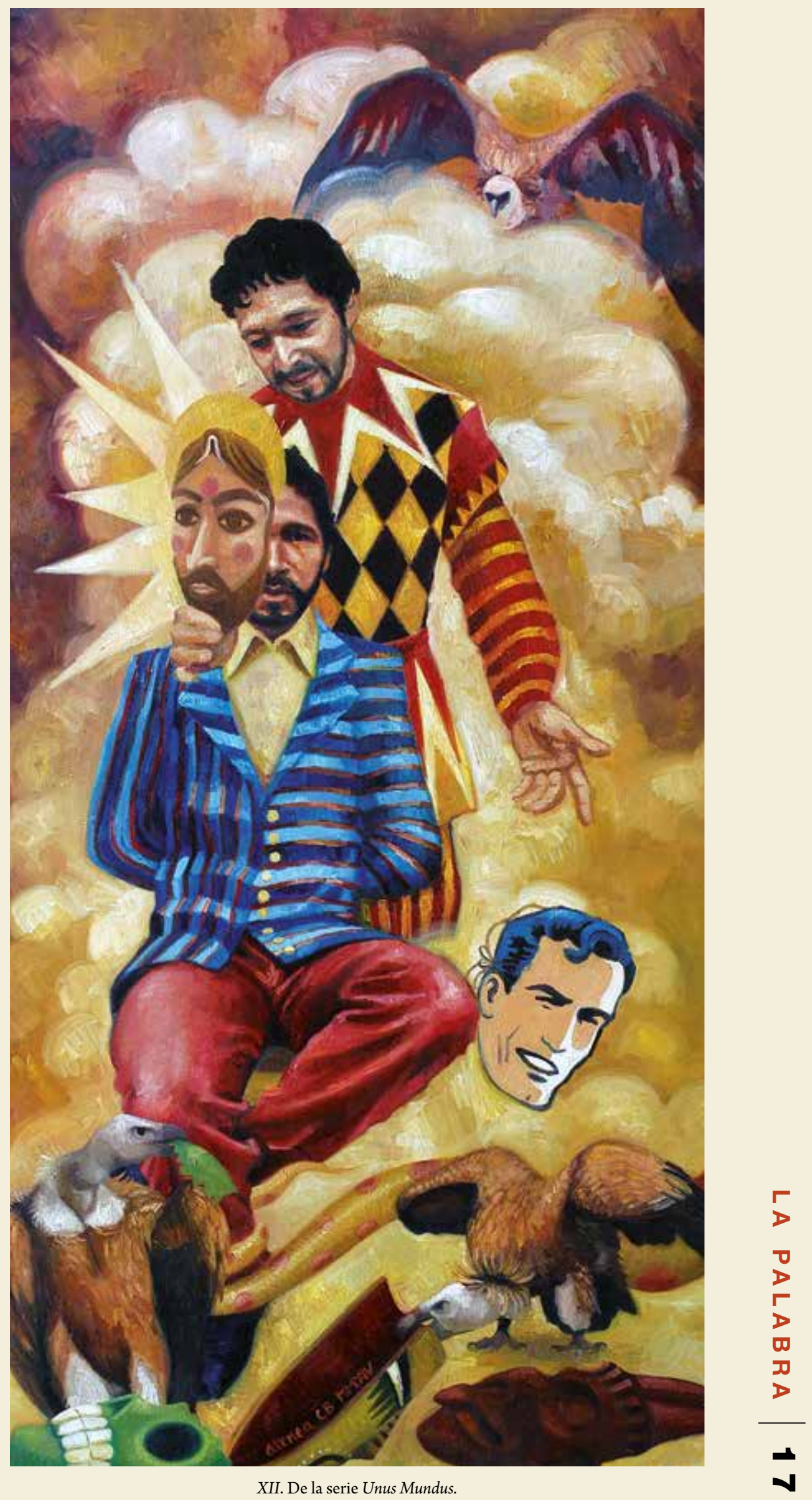


rífero, debido a una temprana paraparesia- reunía para la ocasión. Casi todos ellos iban convencidos por el dinero que se les prometía; otros, los menos, seguramente por la curiosidad y el genuino deseo del encuentro.

Una vez iniciada la tertulia, los jóvenes se desnudaban, sin ningún pudor, bajo las miradas lúbricas de los mayores, quienes, uno a uno, iban tomando y encendiendo un cigarrillo para luego, con mucho cuidado y no sin riesgo de una ligera quemadura, colocar el pitillo ardiendo entre las nalgas de cada jovencito; algunos adolescentes con más pericia que otros no solo eran capaces de sostenerlo bien apretado, sino que también tenían el talento de mantener viva la brasa que hacía arder el tabaco: el truco era la previa ingesta, durante el día, de alubias y otras legumbres, y durante la noche, de agua gasificada exclusivamente para producir exhalaciones intestinales suficientes y delicadas como para encender la intermitente ascua del cigarro.

Tras este simple pero meticuloso preparativo, las luces se extinguían, una por una, dejando todo el vergel a oscuras. Entonces, la aguja de la tornamesa iba rayando en la oscuridad, apagando el sonido de los pasos y el corretear de los púberes; no se escuchaba nada más que la música que sonaba amplificada el Glühwürmchen Idyll de Lincke, a solicitud de uno de los asistentes -un melómano, antiguo agregado cultural del servicio diplomático mexicano en la Polonia de Gierek-. Mientras, los cetrinos efebos, con los cigarrillos ardiendo en medio de sus culos, corrían como podían a "esconderse", unos detrás de un guarumbo $\mathrm{y}$ otros tras los varios árboles jonotes del jardín; todo aquello simulaba la ronda nocturna de los cocuyos. Los señores que asistían como invitados daban inicio a la caza, y así como los niños en las noches veranas atrapan en frascos vacíos a las luciérnagas, ellos perseguían las luces diminutas de los cigarros que delataban al joven que lo portaba; y entonces se iban -como los poetas, en palabras de Gombrowicz-guiados por luciérnagas voraces, se van, se vienen, ya van... se alejan ... y tornan feroces, dando a la mirada cal, a sus palmas hielo, ardores fugaces, que vienen $y$ van, rotando espirales hacia ninguna parte. Corrían presurosos tras las centellas para dar alcance a los nínfulos y, entre las plantas grandes del jardín, arrancarles los cigarrillos de entre sus nalgas, para penetrarlos sin mayor reserva, o para tomarlos por las angulosas crestas ilíacas, e hincarse, penitentes y piadosos, para libar suavemente del néctar de sus cuerpos.

Entretanto las matas, testigas silenciosas en la noche cerrada, iluminada escasamente por los muchachos luciferinos, se asomaban desde la maleza para ver los encuentros ciegos de la carne envidiada. Y las flores se desaletargaban cuando de la cópula entre varones hedía el perfume merdoso, aroma que se alzaba por el aire, sugerente, para las orquídeas epífitas que se mecían en las ramas de los árboles, como niñas que en los columpios sonríen traviesas a hombres desconocidos que las observan a la distancia. Los olores almizclados provocaban que los trichoceros sacudieran sus moscas que de ardid llevaban en flor. Esto las hacía lucir más vivas que cuando, engañosas, atraen al incauto macho mosca que se aparea con sus pétalos, burlado, sin darse cuenta, del embuste de los tramposos trichoceros que solo quieren ser polinizados.

$$
\text { *** }
$$

En esta ocasión, me parece que conviene a la historia escoger a un par de actores, de entre todos los personajes reunidos en ella, para que hagan lo que han venido a hacer, no más; que, actanciales, se accionen cuando para la historia sea justo, precisamente ahora cuando el idilio entre los hombres debe ser consumado, para solaz o estupor: cerca de los juncos de un estanque negro, uno de los invitados, de profesión maestro -formado en la desaparecida Escuela Normal Rural que estuvo en Ximonco, a las faldas del Cofre de Perote, que en 1969, en una acción sorpresa, fuerzas regulares del Ejército Mexicano tomaron coactivamente para desmantelarla-, único profesor de una escuela perdida en el bosque montano, a kilómetros lejos de la finca, alcanzó a un muchachito que a punto estuvo de terminar adentro de la laguna simulada, donde descansaban, anfibios, los lirios acuáticos. Faltó muy poco para que el muchacho rompiera el agua y perturbara el sueño bufónido de los nenúfares, pero el brazo del maestro, hecho un garfio, lo enganchó. Lo tomó de tal forma, y con tal fuerza lo atrajo hacia él, lanzando por los aires el cigarrillo, que se le desprendió de entre las ancas al jovencito debido al brío cinético de la carrera y la fuerza que la detuvo. El cigarro fue a parar en el estanque, $\mathrm{y}$ apenas sintiendo el agua dejó escapar un tsssss larguísimo, y allí quedó flotando como el cadáver de un ahogado mientras el pedagogo, desesperado, le colocaba al muchachito sus besos en el cuello.

El chico, ya en su alta adolescencia, se dejaba hacer por el maestro con la mirada extraviada en la penumbra del jardín, pensando que toda ella se le figuraba los cabellos negros de su mujer, su cabellera nocturna recién lavada. Y que los besos que se le iban derramando sobre el cuello, primero, y por todo su cuerpo, después, eran de ella, de su joven esposa - una niña quinceañera apenas- que dormía mientras tanto, seguramente tranquila, 
pues al acostarse esa noche, en donde fuera que durmiera, pensaba en él, en los alimentos y en el dinero que traería consigo temprano, en los dos listones satines que prometió comprarle para que se adornara bien las trenzas que a él tanto debían de gustarle; mucho le gustaban, ciertamente, se convencía el muchacho, Pirilampo - porque hay que llamarlo por algún nombre y este, en realidad, era el apodo por el que respondía desde que era un niño-; se convencía Pirilampo, entonces, de cuánto le gustaban las trenzas enlistonadas de su mujer, sintiendo el peso abdominal del profesor sobre su espalda; mucho le gustaban sin duda.

El encuentro fue breve: el maestro rural no tardó más allá de un momento en deshacerse, en un orgasmo, dentro de Pirilampo. Todo terminó en un instante, justo cuando el cielo, en un espasmo, se descubrió de nubes y derramó, seminal, todas sus estrellas.

Cayeron sobre la hierba al mismo tiempo. El maestro fue ensombreciendo su entusiasmo. Rendido sobre el herbaje, rompió el silencio de pronto: nostálgico, comenzó a canturrear quedito, muy quedito, una canción que era casi como un murmullo. Pirilampo escuchó que iba diciendo: cocuyito playero / ilumina el sendero / con tu linterna de plata / dame luz / cocuyito playero / tú sabes que te quiero / llévame a mi casita en Veracruz. Y escuchando la cancioncilla del maestro como lo hacía, se le ocurrió la idea: tomar los 500 pesos que le pagaría el venezolano paralítico esa noche para comprar dos pasajes, ida y vuelta, a la costa, y así llevar a su mujer a conocer juntos el mar. Planeaba esto acostado allí en el jardín, desnudo, dejando escurrir fuera el semen del maestrito, quien seguía entonando la canción de Cri-Cri en voz muy baja, acallada por un largo suspiro

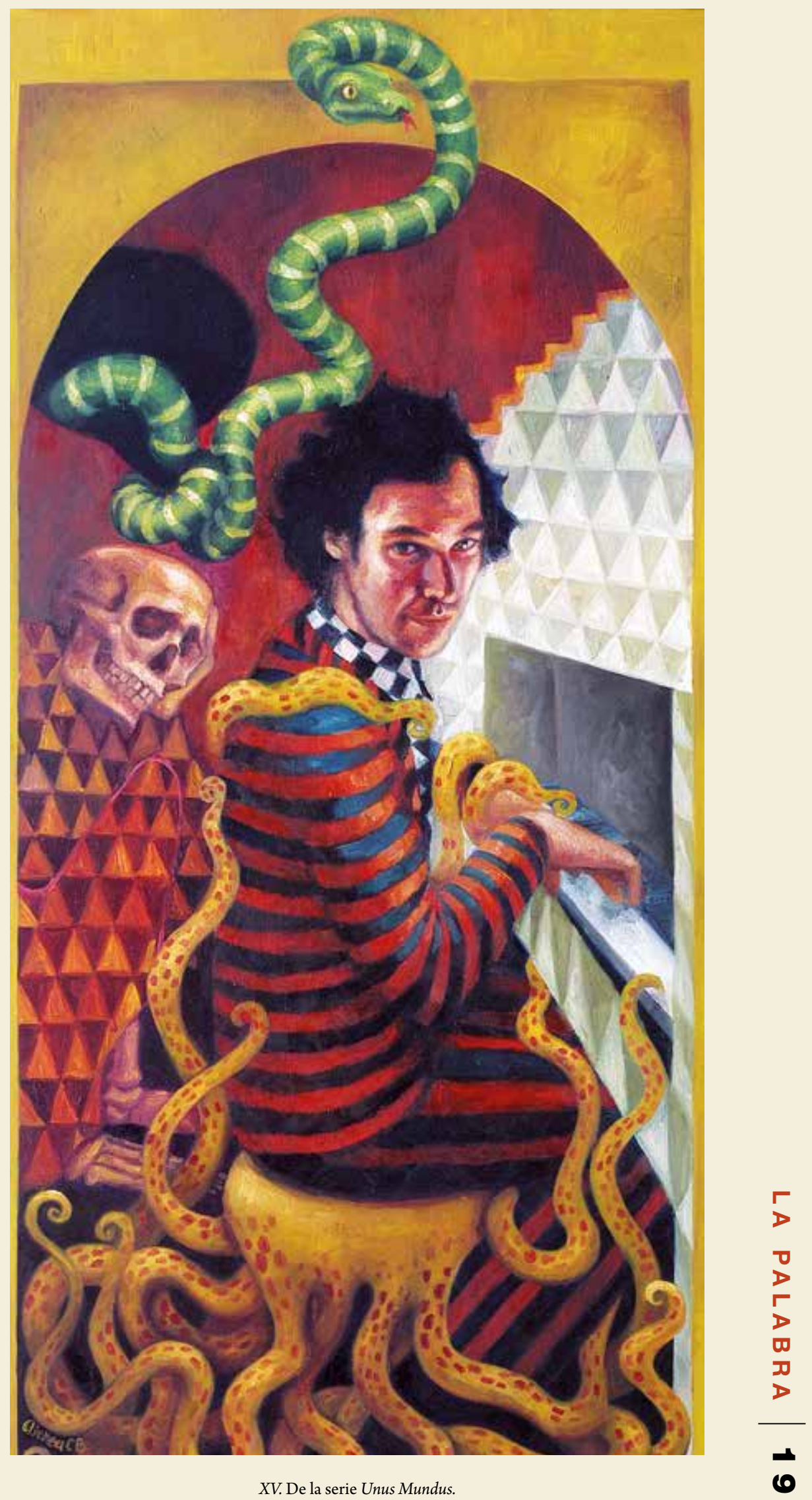




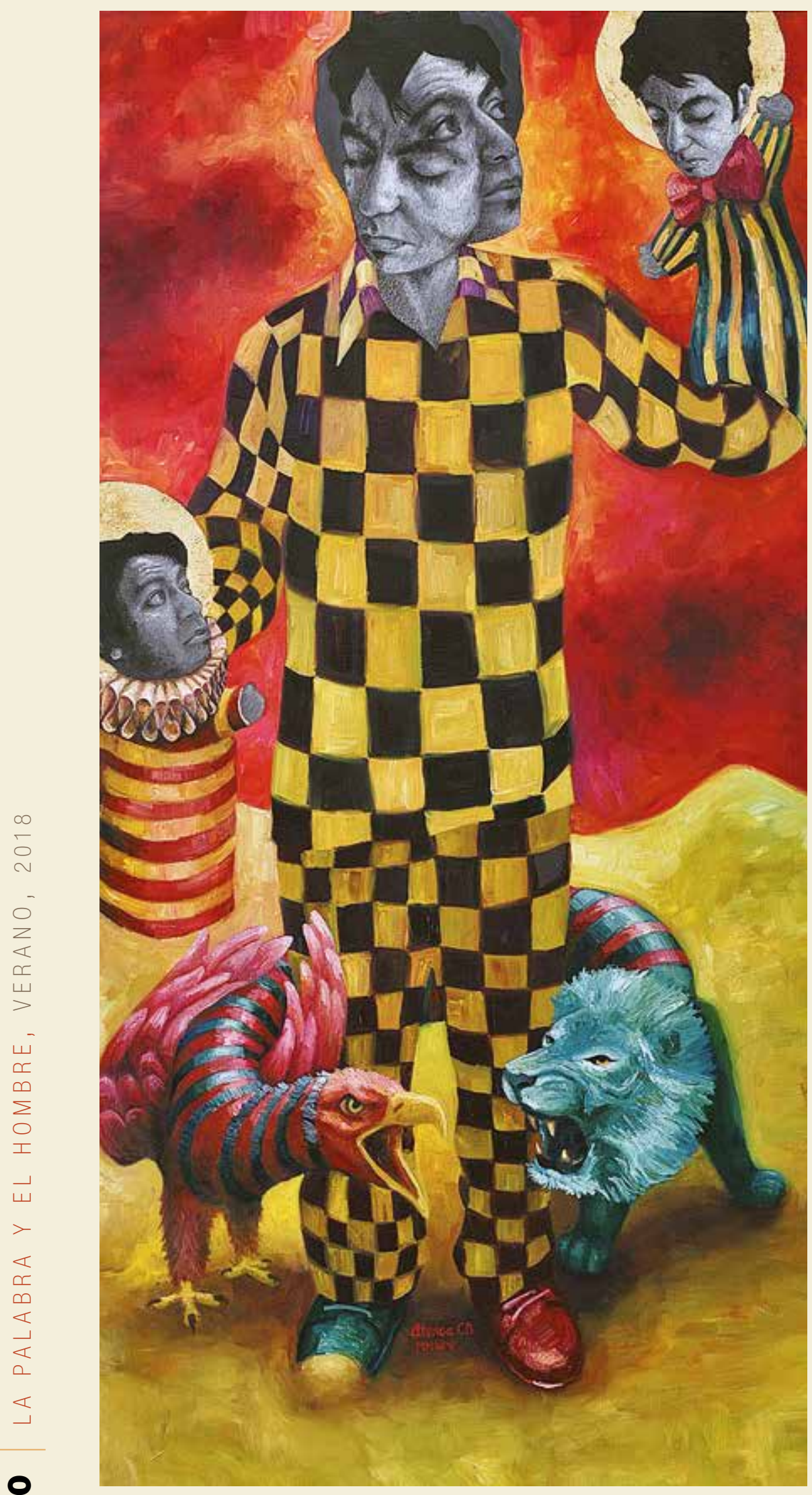

o por el resuello hondo que dejaban escapar los otros convidados al banquete entomófago, perdidos quién sabe en qué parte del vergel; esos otros hombres que - palabras prestadas de Virgilio Piñera- seguían tratando de echar a andar a la bestia cruzada de cocuyos.

Mientras, la noche metida entre las aguas del río, hecha ella un jovencito negro zambo, estiró su brazo anunciando el final a la nocturnata para alcanzar con la mano la roca lunar que en su palma lucía como una pastilla blanca de jabón y como tal utilizó, haciendo con ella espuma suficiente, que lavó con el agua dulce del río. Así, con la luna, la noche se frotó bajo las axilas, la pasó, suavemente, a lo largo de sus brazos y de su pecho. Con ella intentó lavar su espalda. Enjabonó también su cuello y el rostro, luego sus pantorrillas, los nudos de sus articulaciones y los muslos. La noche, con su cuerpo de hombrecito mulato, se enjuagó toda completa, completita, y se llevó entonces la roca lunar, hecha con pasta de jabón, hasta sus genitales; se acarició con ella su inmensa bolsa escrotal y se frotó con la espuma su verga erecta, y descubrió su glande con delicadeza para jabonarlo. La noche se lavó todos los besos y caricias que en ella, ocultos los hombres, esa noche de cocuyos fugaces se habían dado. La noche, al final de su baño, lanzó con fuerza muy lejos, sobre el cielo, la pastilla redonda de jabón, que volvió a su sitio que no era otro sino el de la luna. LPyH

Lino Monanegi (Coatzacoalcos, 1988) estudió Lengua y Literatura Hispánicas en la uv. Fue beneficiario del PECDA Veracruz (emisión XIX) y becario de la FLM (2017). Actualmente, es beneficiario del PECDA Veracruz en la categoría de Jóvenes Creadores (emisión XXII). 